\title{
Mathematical Modeling Contest Based Innovative Talents Cultivation and Higher Mathematics Teaching Reform in Higher Vocational Colleges
}

\author{
Xiaoping Jiang \\ Liaoning Mechatronics College \\ Dandong, Liaoning, 118009, China
}

\begin{abstract}
The cultivation of innovative talents has gradually become an important goal of talent cultivation in higher vocational colleges. Educational workers in higher vocational colleges have carried out a large number of education and teaching reforms to achieve this goal. As a national-level academic competition to cultivate students' application ability and innovation ability, the Mathematical Contest in Modeling has been paid more and more attention by higher vocational colleges. Mathematical modeling is a bridge between mathematics and application. Based on the integration of enterprises with vocational colleges, this work introduced the teaching reform process and achievements of the higher mathematics course, which takes the Mathematical Contest in Modeling as a carrier. In addition, it also introduced a mathematical modeling technician class which carries out the teaching reform with the application as the subject and project as the guidance.
\end{abstract}

Keywords-Mathematical modeling; Technician class; Contest; Innovation ability; Higher mathematics; Teaching reform

\section{INTRODUCTION}

Higher mathematics courses in higher vocational colleges have not been valued by students for a long time. Students have always lacked interest in mathematics since they think that mathematics is not a professional course and is just a course with boring theoretical calculation. They do not see how mathematics works and they do not realize how important mathematics is. It is inevitable to carry out mathematics teaching with application as the main purpose in order to let students know how to use mathematics and when to use it. This work set up a mathematics modeling technician class with the Mathematical Contest in Modeling to explore mathematics teaching in vocational colleges, and to attract and organize excellent higher vocational colleges to participate in the modeling contest [1]. This research idea and method are relatively rare in higher vocational colleges at present, which can be used for reference and promotion in other higher vocational colleges.

\section{Establishing A New Higher MATHEMATiCS \\ TEACHING MODE WITH APPLICATION AS THE SUBJECT AND PROJECT AS THE GUIDANCE BASED ON THE MATHEMATICAL CONTEST IN MODELING}

The higher mathematics curriculum is an important part of

2018 Annual Vocational Education Key Education Public Foundation Course Project: Deepening the Reform of Higher Mathematics in Higher Vocational Colleges Based on the Integration of Enterprises with Vocational Colleges (No. 2018GGJCKT153). the higher vocational education curriculum system and the indispensable teaching content of higher vocational education. The ideas and methods of higher mathematics play an important role in professional learning, skill development and professional ability improvement of students. The mathematics curriculum is the foundation for learning all natural sciences and social sciences; therefore, the quality of students' mathematics foundation will directly affect the study of professional courses.

Taking the Basis of Circuit Analysis, Analog Electronic Technique and Digital Electronic Technique as examples, the statistical analysis regression method can be used to obtain the correlation between the higher mathematics scores and the above three academic scores.

TABLE I. CORRELATION TESTING AND PARAMETER ESTIMATION OF HIGHER MATHEMATICS SCORES AND RELATED COURSES

\begin{tabular}{cccc}
\hline Course Parameters & $\begin{array}{c}\text { Circuit } \\
\text { Analysis }\end{array}$ & $\begin{array}{c}\text { Analog Electronic } \\
\text { Technique }\end{array}$ & $\begin{array}{c}\text { Digital Electronic } \\
\text { Technique }\end{array}$ \\
\hline R (Correlation & 0.57 & 0.524 & 0.589 \\
Coefficient) & & 0.844 & 0.551 \\
a (Slope) & 0.704 & 5.293 & 32.601 \\
b (Intercept) & 7.546 & .
\end{tabular}

The goal of talent cultivation in higher vocational colleges is to cultivate high-skilled talents with various professional abilities and innovative application talents with sustainable development [2].

Students have always lacked interest in mathematics since they think that mathematics is not a professional course and is just a course with boring theoretical calculation. They do not see how mathematics works and they do not realize how important mathematics is. It is inevitable to carry out mathematics teaching with application as the main purpose in order to let students know how to use mathematics and when to use it.

Mathematical modeling is an important bridge connecting mathematics and application, and it is the only way for mathematics to be applied [3].

Based on the "China Undergraduate Mathematical Contest in Modeling", establishing mathematical modeling technician class and carrying out mathematical modeling activities have become an effective way to reform and innovate the higher mathematics curriculum [4]. Through the establishment of mathematical modeling technician class, the idea and method 
of mathematical modeling will be integrated into higher mathematics classroom teaching in higher vocational colleges, with the application as the subject and the project as the guidance, so as to strengthen the cultivation of modeling ability and solving ability of students and enhance their practical application ability.

\section{IMPLEMENTATION PROCESS}

The new mode of higher mathematics teaching should be practiced in the mathematics modeling technician class. Mathematical modeling can be transmitted to each student in a point-to-point manner can stimulate students' independent learning enthusiasm and team communication and cooperation ability through closely combining mathematics modeling with technician classroom teaching, mathematical modeling association community activities and participation in mathematical modeling competitions. In the problem situation and project-based learning, the mathematics modeling teaching should be implemented in a down-to-earth and leisurely way to cultivate the core qualities of moral education. Mathematical modeling is conducive to improving students' verbal expression ability, and the thesis that clearly and smoothly illustrates the modeling ideas, assumptions, methods, results and other contents is the concentrated embodiment of the achievement.

Mathematical modeling technician class can be organized through the selection of students. It should develop a talent training program for mathematical modeling technicians, and develop teaching content, teaching plan, and assessment plan. What is more, it should also organize and train outstanding students to participate in the Mathematical Modeling League in three northeast provinces of China, and organize the training of the "China Undergraduate Mathematical Contest in Modeling 2019".

\section{A. Basic Mathematical Modeling Teaching}

The basic modeling ideas and basic modeling methods for the students in the mathematical modeling technician class are the extension and application of higher mathematics knowledge.

The lectures include excel data analysis, probability theory and mathematical statistics, linear algebra, mathematical modeling methods, mathematical model solving using Matlab software, and paper writing.

\section{B. Intensive training for the Mathematical Contest in Modeling}

Based on the real questions of previous years, intensive training of project-oriented teaching should be implemented to decompose the project. Adopting the task-driven approach to introduce comprehensive modeling methods can strengthen students' concept of using mathematical modeling to integrate the problem. By contacting various types of practical problems, students are able to improve their modeling ability comprehensively. The teaching process is interlocking and attracts students to actively explore and solve problems, which can encourage students to pay attention to social hot issues, such as the college entrance examination, optional class system, air pollution problems and real-time monitoring of air quality.
Therefore, students can pay more attention to social phenomena and love life [5].

\section{Learning method of mathematical modeling}

Three team members form a learning group, and the team leader is responsible for communication, division of labor and cooperation. With the help of the Internet information teaching platform, students can improve their learning ability and problems-solving ability. Students can also promote their self-learning ability, innovation ability, practical ability and comprehensive quality.

\section{Thesis writing and defense}

In the process of preparing for the defense, students can have a deeper understanding of all aspects of the problem, and have a new understanding of the ways and methods to solve the problem.

\section{E. Knowledge lecture about mathematical modeling}

Through lectures about mathematical modeling knowledge, more and more students will understand mathematical modeling, improve their enthusiasm for learning mathematics, and improve the quality of mathematics teaching.

\section{INNOVATION}

The "China Undergraduate Mathematical Contest in Modeling" is held annually by the Higher Education Department of the Ministry of Education and the China Society of Industrial and Applied Mathematics. The topics are from practical problems in real life and research activities, which are application-oriented and open-ended. Therefore, answering the entry questions requires a combination of mathematical methods, computer technology and related background knowledge to bring into play the collective wisdom, cooperative spirit and creative thinking of the team [5].

The "China Undergraduate Mathematical Contest in Modeling 2019" was held on September 12, 2019, from 18:00 to 12:00. Eighteen students from six teams in Liaoning Mechatronics College submitted theses within the specified time through the study in mathematical modeling technician class, the special training before the competition, and the teamwork of three days and three nights, which realized the breakthrough of zero.

A. Based on mathematical modeling, a new mode of higher mathematics teaching with application as the subject and project as the guidance is adopted

Mathematical modeling is an effective method of cultivating students' practical innovation and improving students' comprehensive ability.

Through the Mathematical Contest in Modeling, the enthusiasm of students to learn mathematics can be mobilized. The real use of mathematics and the ability to use mathematical thinking to solve practical problems attract students to explore and innovate, which will improve students' comprehensive quality, learning ability and innovation ability. 


\section{B. Taking the "China Undergraduate Mathematical Contest in Modeling" as the carrier and setting up mathematical modeling technician classes}

Higher vocational colleges should formulate a talent training program, teaching plan and appraisal program suitable for the mathematics modeling technician classes, then organize students to participate in the mathematical modeling contest, and finally organize thesis defense in terms of the theses submitted for the contest.

The number of schools participating in the "China Undergraduate Mathematical Contest in Modeling" in 2018 has shown a steady state. The size of the undergraduate group has exceeded $10 \%$, and the number of higher vocational colleges participating has increased slightly in the past two years. In 2018, a total of 28 teams from 8 institutions participated in the contest. Attracting and organizing excellent higher vocational colleges to participate in the modeling contest is the work of several modular committees to further summarize the experience and study. This research idea and method are relatively rare in higher vocational colleges at present, which can be used for reference and promotion in other higher vocational colleges.

In 2019, a total of 30 teams from 8 institutions in Liaoning Province signed up for the contest and 28 teams submitted theses and successfully completed the contest. It is worth mentioning that 6 teams won the second prize of national, the first prize of Liaoning division, the second prize and the third prize.

\section{Innovating teaching methods}

Vocational colleges should explore the combination of theoretical learning and applied practice, make full use of the Internet information teaching resources and adopt the captain responsibility system. The innovative talent cultivation and comprehensive quality education combined with individual efforts and group cooperation is a breakthrough to the traditional teaching methods and improves teachers' teaching level and scientific research ability.

D. Promoting the teaching reform of higher mathematics curriculum system, content and methods can improve the teaching quality of higher mathematics courses

The Mathematical Contest in Modeling is a rare and exploratory practical training for students. It simulates the situation of finding practical solutions to practical problems after graduation, enriches and activates students' extracurricular life, creating conditions for outstanding students. The Mathematical Contest in Modeling helps to train students' imagination, insight and creativity, cultivate their spirit of unity and cooperation, organizational skills, and literature review, data collection and written expression ability [6].

\section{ACHIEVEMENTS}

\section{A. The Mathematical Contest in Modeling achieved excellent results}

In 2019, 2 teams of Liaoning Mechatronics College won the first prize and 2 teams won the third prize in the Mathematical Modeling League in three northeast provinces of China.

In 2019, 1 team of Liaoning Mechatronics College won the first prize, 1 team won the second prize and 2 teams won the third prize in the "China Undergraduate Mathematical Contest in Modeling". In addition, the thesis of the team that won the first prize won the second prize in the national specialist group and the second prize in the Liaoning division.

By participating in the Mathematical Contest in Modeling, students can find the best solution through mutual discussion and research. Some students concluded that this contest can be said to be an unprecedented learning experience which bright them lifelong benefit. Promoting mathematics teaching with contest activities lets students enjoy the joy of learning brought by the challenge, and promote learning by contest. The contest is an effective way to cultivate students' practical ability and an important method to improve students' comprehensive ability.

\section{B. Significant improvement in higher mathematics test scores}

The mathematical analysis of the higher mathematics scores of the students in the 17th and 18th grade majored in automatic control before and after the mathematical modeling activities was carried out using the mathematical software Matlab. The T-test was used to find that at the significant level of $\alpha=0.05$, the higher mathematics scores of mathematical modeling activities were significantly improved. 


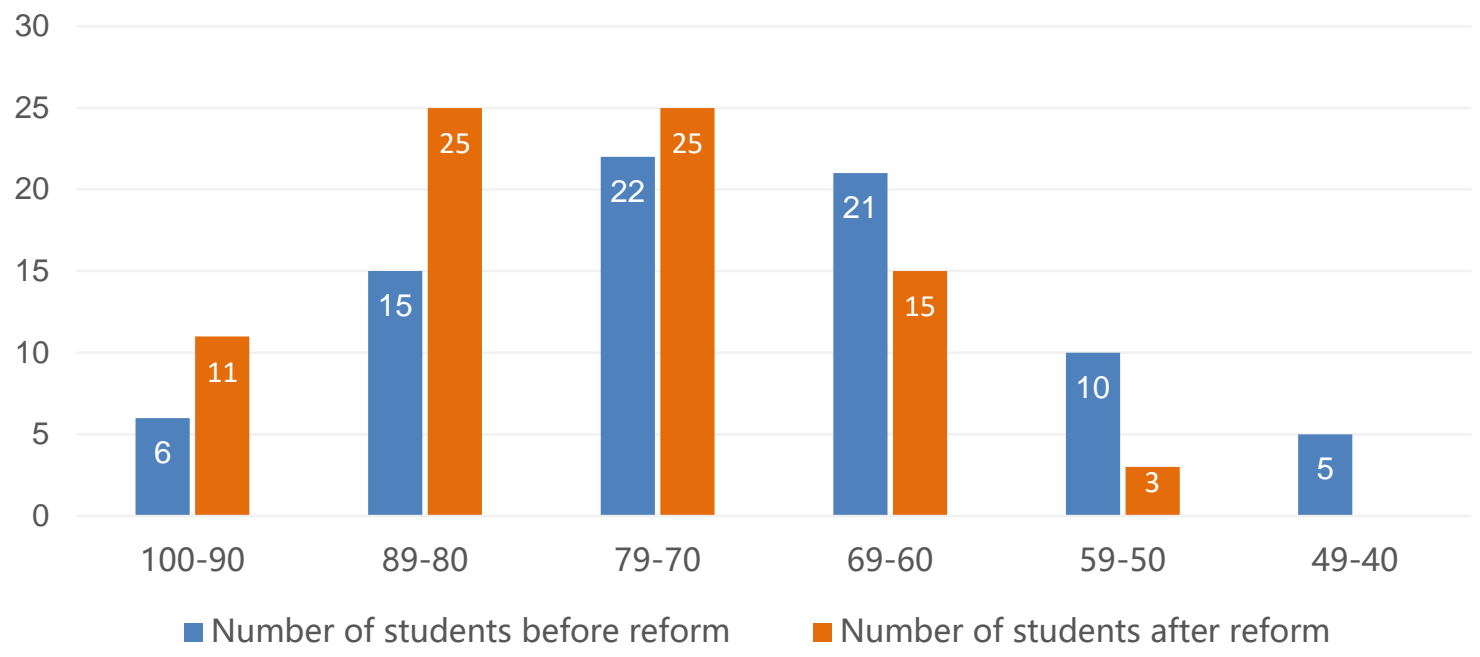

Fig.1. Histogram of higher mathematics achievement frequency before and after curriculum reform

\section{SUMMARY}

Through the development of mathematical modeling activities, students' enthusiasm for learning mathematics to participate in mathematical modeling activities has been greatly mobilized. The contest topics are all derived from the real problems in real life. Higher vocational students do not know how to use mathematics and when to use it, so they lack the enthusiasm for learning mathematics. However, the contest makes students truly understand mathematics. Mathematical modeling is a new model of innovative talent training and mathematics teaching reform that combines theoretical learning with practice. Mathematical modeling fosters and enhances students' cooperative spirit and team awareness, and provides students with a platform that can fully demonstrate their intelligence quotient and develop their spirit of cooperation. The contest also promotes teachers' teaching level and research level, and improves the quality of higher mathematics course teaching.

\section{REFERENCES}

[1] Xie Jinxing. The Experience Exchange Meeting of 15th National China Undergraduate Mathematical Contest in Modeling.

[2] Liu Chunying. Using Mathematical Modeling as a Breakthrough to Promote Higher Mathematics Teaching Reform in Higher Vocational Colleges[J]. Journal of Changchun Institute of Education in June 2011.

[3] Jiang Qiyuan, Xie Jinxing, Ye Jun. Mathematical Model (Fifth Edition). Beijing: Higher Education Press, 2018.

[4] Zhao Jinghui. Research and Practice on Establishing Personalized Personnel Training Mechanism in Higher Vocational Education[J]. Journal of Liaoning Higher Vocational College, 2018, 11.

[5] China Undergraduates Mathematical Contest in Modeling Website.

[6] Jiang Qiyuan, Xie Jinxing, Ye Jun. Mathematical Model (Fifth Edition). Beijing: Higher Education Press, 2018. 